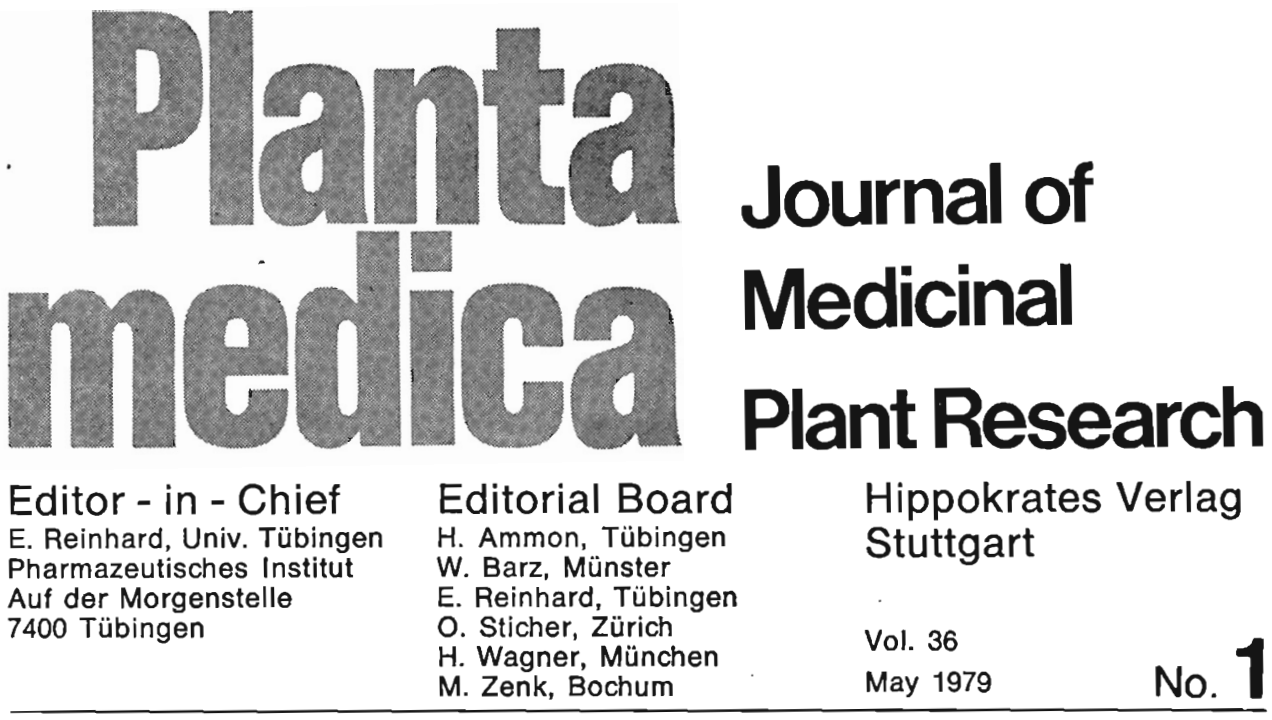

Review Amtiche

\title{
Biosynthesis of Isoquinoline Alkaloids
}

\author{
J. Staunton \\ University Chemical Laboratory, Lensfield Road, Cambridge, U.K.
}

Key Word Index: Biosynthesis; Isoquinoline Alkaloids.

\section{Abstract}

The isoquinoline alkaloids and their biosynthetic relatives include many compounds which show important physiological properties in animals: dopamine, mescaline, morphine, papaverine, and narcotine are pertinent examples.

The biosynthetic routes to the members of this family start from the essen- tial aminoacids tyrosine or phenylalanine. Decarboxylation gives a phenethylamine building block $\left(\mathrm{C}_{6}-\mathrm{C}_{2}\right)$ which then combines with an additional building block to form an isoquinoline ring. This stage of the general biosynthetic scheme is illustrated by the biosynthesis of the cactus alkaloid anhalonidine.

Many important classes of alkaloid are produced by further transformation of simple isoquinoline systems. In 
the opium poppy the benzylisoquinoline reticuline is converted to the two very different alkaloids morphine and narcotine. More recently it has been estblished that two of the alkaloids of Stephania japonica, protostephanine and hasubanonine are also produced by modification of a benzylisoquinoline precursor.

These varied biosynthetic pathways and the methods used in their elucidation are discussed in detail.

The isoquinoline alkaloids comprise a diverse family of natural products many of whose members play an important role in medicine. In this connection one need only mention for example morphine and codeine the pain-killers, or emetine which is used to treat amoebic dysentry.

The range of structures to be found in this family starts with the relative simple tetrahydroisoquinoline derivatives shown in Scheme 1. The first three types are found in cacti; benzylisoquinolines related to (4) and phenethylisoquinolines based on (5) are produced in many types of plant. The general structure of these more simple isoquinoline systems is shown in (6). Each diagram is marked in heavy type to indicate the way in which the structure might be built up from simpler building blocks. It will be clear that in each case a phenethylamine unit is converted to an isoquinoline by combination with a second building block of varied structure. As we shall see later this analysis of their structural relationship is reflected in their biosynthesis.

Scheme 2 shows a selection of more complicated isoquinoline alkaloid structures. The aporphine skeleton (6) is recognisably an isoquinoline derivative as are those of the morphinans (7), the protoberberines (8), the phthalideisoquinolines, (9), and the erythrina alkaloids (10). At first sight the inclusion of (11) the basic skeleton of the alkaloid

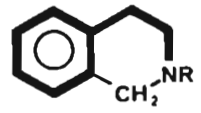

(1)

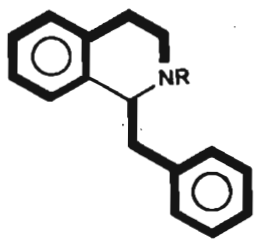

(4)

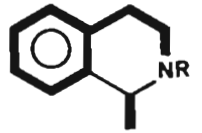

(2)

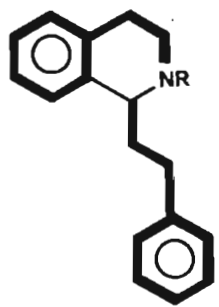

(5)

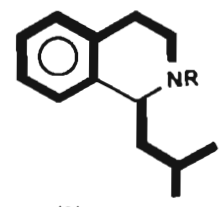

(3)

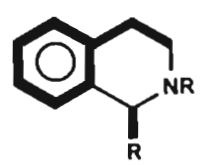

(6)

Skeletal Structures of Simple Tetrahydroisoquinoline Alkaloids Scheme 1 


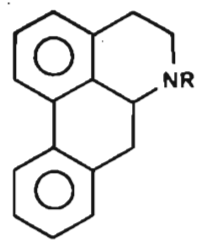

(6)

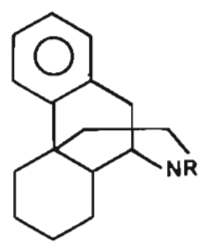

(7)<smiles>[Mg]</smiles>

(8)

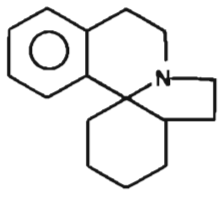

(10)

(11)

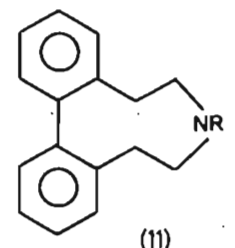

Precursors

Scheme 2

protostephanine seems inappropriate isoquinoline structures are elaborated but as we shall see later, this alkaloid to more complicated systems such as is derived via benzylisoquinoline pre- those illustrated in Scheme 2. Our curcursors (as are all the other systems rent understanding of the early stages illustrated in Scheme 2) and so it is rea- of isoquinoline alkaloid biosynthesis sonable to list it as a member of this extensive alkaloid family. owes much to the pioneering studies carried out on the origin of the three alkaloids (12), (13), and (14) produced by the cactus Lophophora williamsii. These alkaloids have long been of interest on account of their hallucinogenic properties.

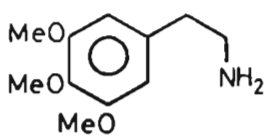

(12) mescaline

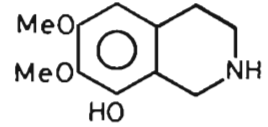

(13) anhalamine<smiles>COc1cc(O)c2c(c1)CCNC2C</smiles>

(14) anhalonidine

Scheme 3 Alkaloids of Lophophora williamsii 
The two isoquinoline alkaloids bear an obvious structural relationship to each other and also to their phenethylamine congener mescaline. Early feeding experiments showed that as is so of ten the case, tyrosine is the precursor of the phenethylamine residue $[1,2]$. In Scheme 4 , for example, activity from $2-{ }^{14} \mathrm{C}$ tyrosine was incorporated efficiently into anhalonidine and the specificity of the label in the alkaloid was established by a standard Hofmann degradationoxidation sequence leading to formaldehyde. This was produced exclusively from $\mathrm{C}-3$ of the tetrahydroisoquinoline and as expected the molar activity of this fragment was the same as that of the alkaloid.

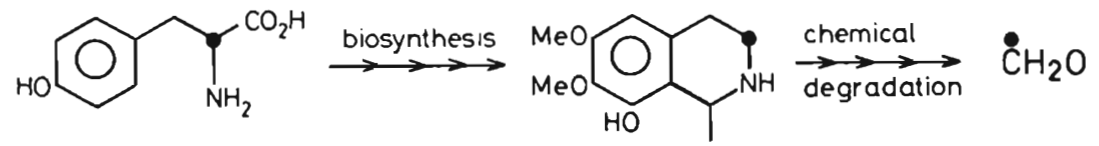

- $={ }^{14} \mathrm{C}$

\section{Scheme 4 Incorporation of Tyrosine into Anhalonidine}

The sequence of steps leading from tyrosine to the various alkaloids has been worked out in great detail by precursor incorporation experiments (Scheme 5) [3-8]. Firstly tyrosine is decarboxylated to tyramine which is then subjected to a sequence of hydroxylation and O-methylation steps which convert it to the key intermediate (15). At this point the pathway branches. O-Methylation at one site of (15) leads to (16), which is further methylated to give mescaline. Alternatively, O-Methylation of (15) at the second hydroxyl gives (17) which is ultimately converted to the two isoquinoline alkaloids. Sur-<smiles>NC(Cc1ccc(O)cc1)C(=O)[O-]</smiles><smiles>CCC(=O)Oc1ccc(CCN)cc1</smiles><smiles>C=C</smiles><smiles>NCCc1ccc(O)cc1</smiles>

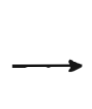<smiles>CCc1cccc(O)c1</smiles><smiles>CCN</smiles><smiles>COc1cc(O)cc(CCN)c1</smiles><smiles>C1CC1</smiles>

(15)<smiles>[R]C1NCCc2cc(OC)cc(O)c21</smiles><smiles>CC(C)(C)C</smiles><smiles>COc1cc(O)cc(CCN)c1</smiles><smiles>COc1cc(CCN)cc(OC)c1</smiles>

(16)

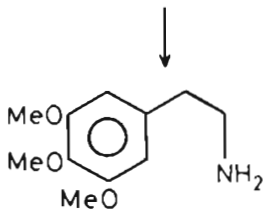

(17)

Scheme 5 Pathway from tyrosine to the alkaloids of L. williamsil 
prisingly perhaps (17) is apparently not converted to mescaline so it would appear that the fate of material as it flows along the pathway is decided by the site of O-methylation of (15).

This general pattern will be seen again later when we come to consider biosynthetic pathways leading to other isoquinoline alkaloids: tyrosine is first elaborated to a suitable hydroxylated and derivatised phenethylamine which is then combined with a second building block to give an isoquinoline. It will have been clear from Scheme 1 that the structure of this second building block can vary widely. At first sight the task of identifying the second unit might seem straightforward but in fact it has often proved to be unexpectedly difficult. The popular view was until recently that the phenethylamine would condense with the appropriate aldehyde to form a tetrahydroisoquinoline directly; a persuasive analogy for this hypothetical scheme can be found in the chemical synthesis of tetrahydroisoquinolines associated with the names of Pictet and Spengler. Nature does not necesssarily follow chemical precedents, however, and in the case of the peyote cactus alkaloids the pathway eventually established [9] is markedly different from this simple expectation. Thus in Scheme 6 the phenethylamine condenses with a suitable ketoacid to form the carboxyderivative (18) of the eventual tetrahydroisquinoline. The extraneous group is subsequently removed in an intriguing oxidative decarboxylation to form an intermediate imine (19); this is reduced to the tetrahydroderivative in a subsequent step. The evidence in support of this scheme is exceptionally strong including as it does the isolation of the two ketoacids of structure (18) as well as positive results from conventional incorporation experiments.

In L. williamsii this pathway operates exclusively but the mode of biosynthesis of the related alkaloid lophocerine (21) in $L$. schottii appears to be less clear cut. Two alternative pathways by which a phenethylamine could be converted to the isoquinoline derivative are shown in scheme 7 . In the first mevalonate is converted to an aldehyde (20) which could combine with a suitable phenethylamine to give the required skeleton. The second pathway starts with leucine (22) and proceeds via steps equivalent to those shown in the previous scheme to a tetrahydroisoquinoline. Surprisingly tracer experiments have provided support for both path-

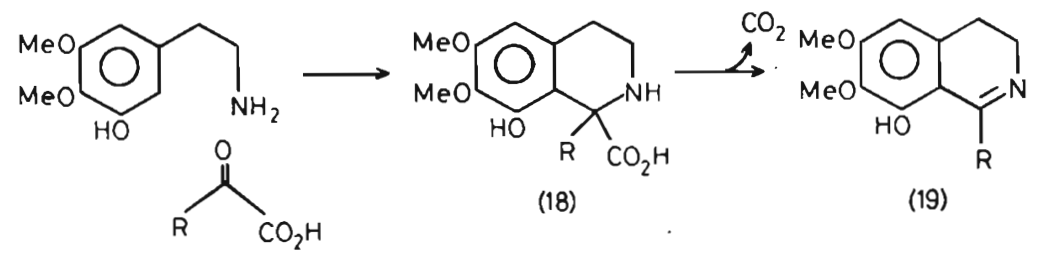

$\mathrm{R}=\mathrm{H}$ or $\mathrm{Me}$

Scheme 6 Generation of the Isoquinoline System in L. williamsil 


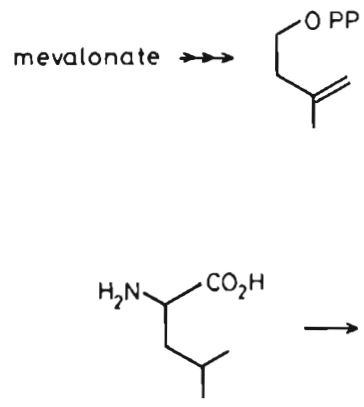

(22)

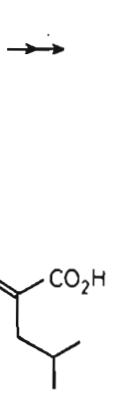

$Y$<smiles>CCC(C)CC=O</smiles>

(20)<smiles>COc1cc2c(cc1O)C(CC(C)C)N(C)CC2</smiles>

(21)

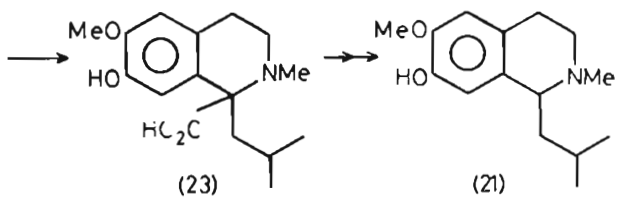

Scheme 7 Lophocerine Biosynthesis in L schottii

ways and so it is possible that in this case both routes operate side by side [10-12].

A number of systems have now been subjected to this type of investigation and the current situation is summarised in Scheme 8. In some instances it would appear that the second building block is incorporated as an. aldehyde [13, 14] whereas in the case of the simpler cactus alkaloids discussed earlier and the benzylisoquinoline alkaloids of the opium poppy $[15,16]$ it is firmly established that the second unit is incorporated in the form of a ketoacid. Looking to the future, the main interest in these early steps lies in the detailed mechanism of such key reactions as the hydroxylation of aromatic rings and the oxidative decarboxylation of 1-carboxyisoquinolines.

Interest in isoquinoline alkaloids biosynthesis does not stop at this point however because the simple isoquinoli-<smiles>NCCc1cccc(O)c1</smiles><smiles>[R]C(C)CC</smiles><smiles></smiles>

(b)<smiles>O=C(O)CCCCCCCCCCCCCC(=O)O</smiles>

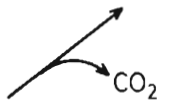<smiles>[R]C1(C(=O)O)NCCc2cc(Cl)ccc21</smiles>

(a) $R=$<smiles>[R]CC1C(C(C)=O)=COC(O)C1C=C</smiles>
Glucose and possibly $\mathrm{R}=\mathrm{Ar}, \mathrm{ArCH} \mathrm{CH}_{2}$ and $\mathrm{Me}_{2} \mathrm{CHCH}_{2}$

(b) $\mathrm{R}=\mathrm{H}, \mathrm{Me}, \mathrm{PhCH}_{2}$ and possibly $\mathrm{Me}_{2} \mathrm{CHCH}_{2}$

Scheme 8 Alternative Routes to Tetrahydroisoquinoline Alkaloids 
nes, we have considered so far can be transformed into a wide range of different structures. This is particularly true of benzylisoquinolines and so the rest of the lecture will concentrate on this class of compound.

Some typical transformations are indicated in Scheme 9 which illustrates the great diversity of skeletal types which can be produced. Those of isoboldine and scoulerine bear an obvious structural relationship to their benzylisoquinoline precursor, but this relationship is less immediately obvious in the case of morphine, and in protostephanine it has been almost completely obscured. Nevertheless the relationship has now been firmly establised in every case as we shall see in the ensuing account.

Before considering detailed case histories it is desirable to introduce one of the key processes, that of oxidative coupling of phenolic rings. The general concept was first enunciated by early pioneers especially RoBINson [17] but the great breakthrough in our understanding of what is involved came when the hypothesis was placed on a sound mechanistic basis by BARTON and CoHen [18]. They pointed out that if a phenolate anion is oxidised to the corresponding radical, the system would have the potential to combine with a second radical species at any one of four sites: at the oxygen itself or at the ring carbons ortho or para to it. The possible out come of such reactions is shown in Scheme 10. First the phenolate (25) is oxidised (by loss of an electron to a suitable acceptor) to the radical (26). Reaction of this at the oxygen leads to (27); reaction at ring carbons leads initially to the three dienones (28), (29) and (30). The former is capable of surviving as such; the remaining two

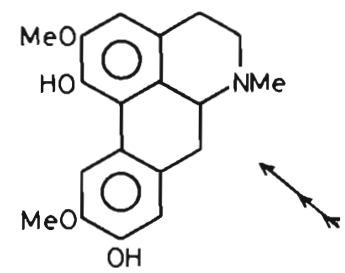

isoboldine

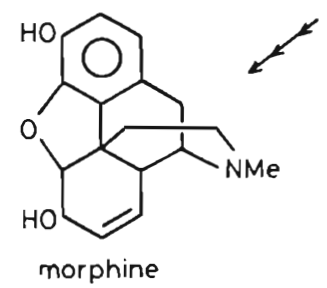

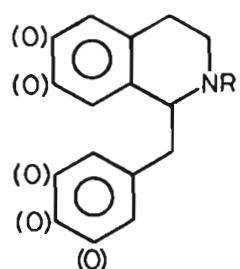

(24)

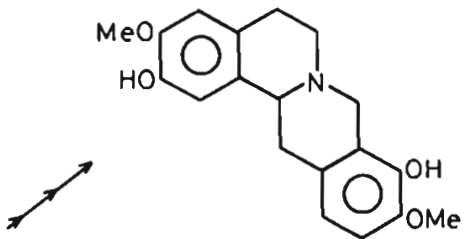

scoulerine

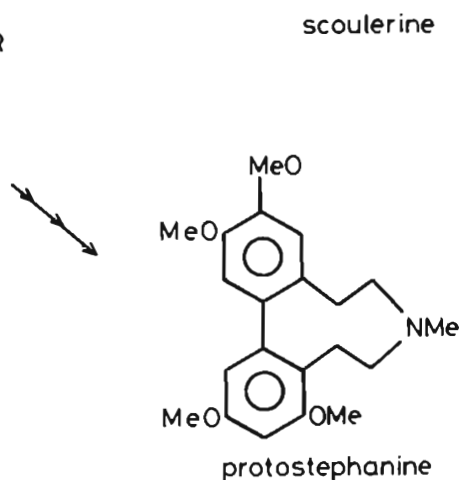


<smiles>[R]c1ccccc1[O-]</smiles>

(25)<smiles>[R]c1ccccc1[18O]</smiles>

(27)<smiles>[R]C1C(=O)[C@@H](C)CC[C@@H]1[Y]</smiles><smiles>[R]c1ccccc1O</smiles>

(26)

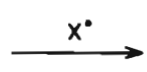<smiles>[R]C1([R])C=CC=CC1=O</smiles>

(28)

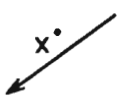<smiles>[R]C1=C[C@@H]([Y])C=CC1=O</smiles>

(31)

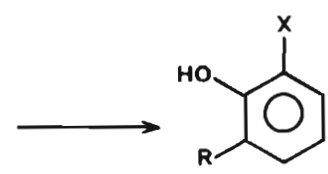

(30) would not be expected to do so because they have a hydrogen at the site of coupling which can be readily lost to regenerate new aromatic products (30) and (32) respectively. Hence the outcome of these radical pairing reactions depends critically on whether or not a substituent is present at the site of attack.

This type of process is the key to the biosynthesis of many different classes of alkaloids. The process is vitally important in the benzylisoquinoline family where there are two linked aryl rings capable of forming phenoxy radicals. In this situation the attacking radical species (equivalent to $\mathrm{X}$ in Scheme 10) may be derived from the second aryl ring as indicated in formal terms in Scheme 11. We now have intramolecular oxidative coupling and it can lead to alternative products such as (34) and (35) (coupling between carbon and oxygen is also known but we will not consider it in detail). The extra C-C bond results in the formation of a different and more complicated skeletal structure and we will go on to consider how the synthetic potential of this reaction is exploited in some representative biosynthetic pathways.

Isoboldine (37) for example has been shown to be formed in Papaver somniferum by a straightforward intramolecular oxidative coupling between the two aryl rings of reticuline (36) [19]. The sites of coupling (marked by dots in Scheme 12) both bear a hydrogen and therefore the two rings can rearomatise to give the biphenyl system characteristic of the aporphine alkaloids, though as we shall see the biosynthetic routes leading to members of this group of alkaloids are not always so straightforward.

It has recently been established that 


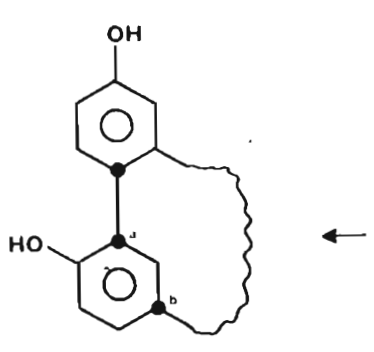

(34)

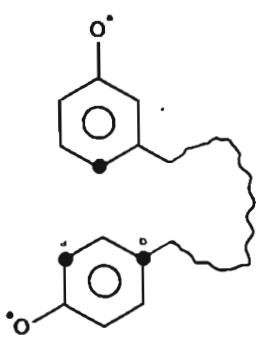

(33)

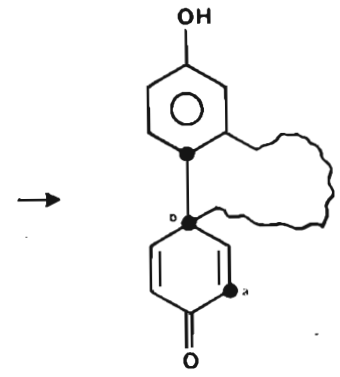

(35)

Scheme 11 Intramolecular Coupling of Phenols<smiles>COc1ccc(CC2NCCc3cc(O)ccc32)cc1</smiles>

(36)

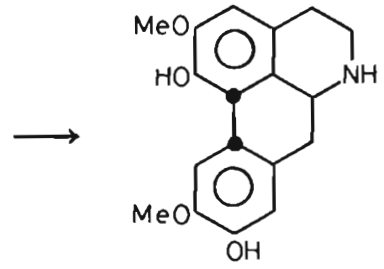

(37) isoboldine

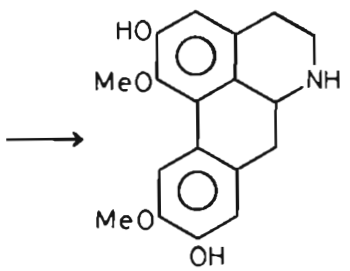

(38) boldine

\section{Scheme 12 Biosynthesis of Boldine}

the isomeric alkaloid boldine (8) is produced in Litsea glutinosa from (37) by demethylation followed by remethylation [20]. This functional group interchange, which is of course incidental to the process which elaborates the carbon skeleton, can cause considerable problems for biosynthetic investigators; whereas the pattern of hydroxyl and methoxy groups in the aryl rings of isoboldine provide a reliable clue to the functionality of its benzylisoquinoline precursor (the new C-C bond is formed ortho to one hydroxyl and para to the other) that of boldine is completely misleading. In a case such as this it may be necessary to test a wide range of pos- sible precursors in order to discover which compounds are the true intermediates.

A second example of straightforward phenol coupling takes place in the biosynthesis of the opium alkaloids thebaine, codeine, and morphine in Papaver somniferum [21]. As can be seen in Scheme 13 reticuline is again the substrate for the coupling step but this time coupling takes place at different sites to give the dienone (38) in which only one of the two rings can rearomatise by enolisation. The carbon framework of the morphinan alkaloids is now established and since the subsequent steps bring about no more than a 


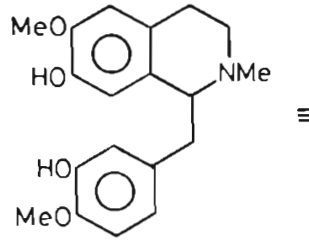

(36)

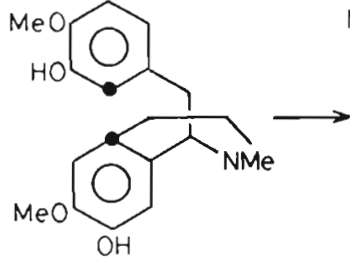

(37)

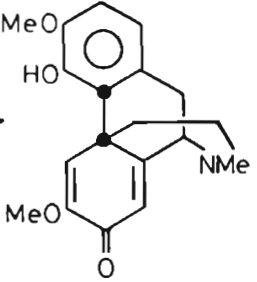

(38)
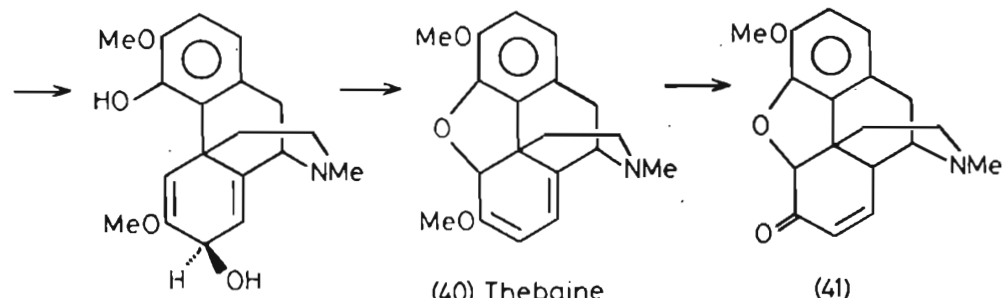

(40) Thebaine

(41)

(39)

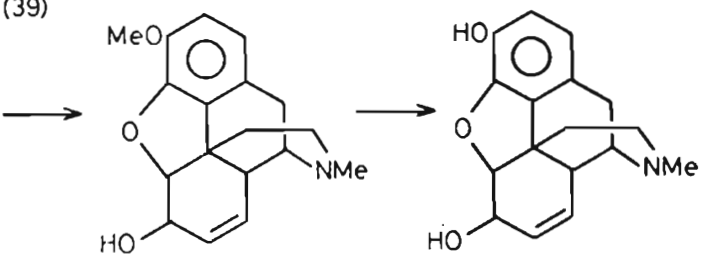

(42) Codeine

(4.3) Morphine

Scheme 13 Biosynthesis. of Morphine

modification of the peripheral functional groups they will not be considered in detail $[22,23]$.

One point which should be stressed at this stage is the importance of the control which must be exerted by the enzymes over the mode of oxidative coupling. Reticuline is the substrate in this key process in both Schemes 12 and 13. Therefore the same diradical is presumably made to couple in two completely different ways. Presumably the enzymes which catalyse the process in each case direct the outcome by forcing the benzylisoquinoline to fold in the appropriate way. The importance of this conrolling influence is brought home by the results of experiments in which chemists attempt to carry out equivalent oxidative coupling reactions in vitro: the usual result is a complex mixture in which the desired product is at best a minor component.

In the two examples discussed so far the carbon skeleton of the final alkaloid is determined by the oxidative coupling and remains unchanged in susequent steps. This is not always the case, however, because cyclohexadienones have a strong tendence to undergo rearrangement. How this can take place is shown in Scheme 14. First in the acid-cataly- 
sed dienonphenol rearrangement the parent dienone (44) is converted to the phenol (47) by migration of a substituent to give a carbonium ion (46) which can aromatise by loss of a proton. An alternative less direct process starts with reduction to the dienol (48) which can now undergo an equivalent rearrangement to give carbonium ion (50) followed by aromatisation to the benzene derivative (51). Both types of process are widely used in alkaloid biosynthesis. Note that the product of the first aromatisation retains the oxygen of the dienone whereas in the second the oxygen is lost. This possibility has to be borne in mind in speculations concerning possible precursors in alkaloid biosynthetic studies [18].

An interesting example of the dienol benzene rearrangement is to be found in the biosynthesis of isothebaine (55) in Papaver orientale [24, 25]. Oxidative coupling of the benzylisoquinoline orientaline (52) (an isomer of reticuline) leads to a dienone (53). This is reduced to the dienol (54) which then undergoes a dienol-benzene rearrangement to form the aporphine isothebaine (55). Note here that there is one less oxygen function in the final product than was present in the benzylisoqiunoline and so once again the pattern of hydroxyl and methoxy groups is profoundly changed in the course of the bio synthesis.

Migration of a substituent is not the only secondary reaction which can lead to modification of the carbon skeleton of a dienone produced by oxidative coupling. Thus in the biosynthesis of the erythrina alkaloid erythraline (60) in Erythrina crista-galli, the initial dienone (57), produced by oxidative coupling of the benzylisoquinoline (56), undergoes cleavage as indicated rather

Dienone-Phenol Rearrangement<smiles>[R]C1([R])C=CC(=O)C=C1</smiles>

(44)
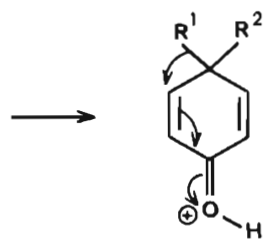

(45)
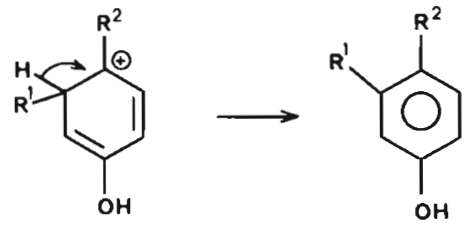

(46)

Dienol-Benzene Rearrangement

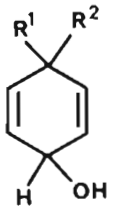

(48)

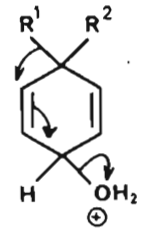

(49)
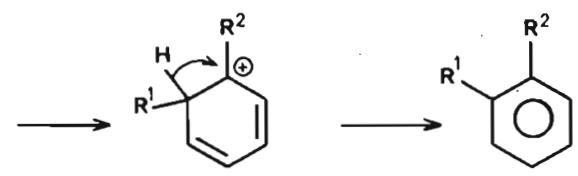

(50) 


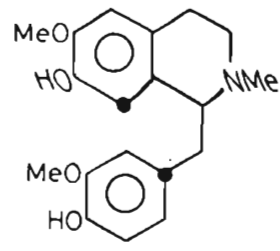

(52)

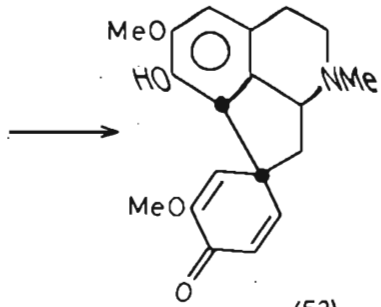

(53)

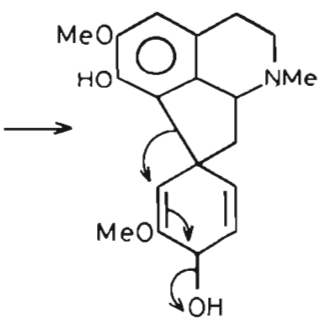

(54)

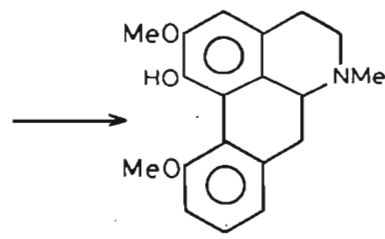

(55) Isothebaine

Scheme 15 Biosynthesis of Isothebaine

than migration of a C-C bond. The product $(58)$ is then reduced to the dihydroderivative (59); we will need to recall these steps later when we consider the biosynthesis of the structurally related alkaloid protostephanine. In this instance the nine-membered ring is subjected to further modification via a recyclisation as indicated leading ultimately to erythraline $[26 ; 27]$.

At this point it is helpful to summarise the processes we have met so far. Firstly intramolecular oxidative coupling of a benzylisoquinoline leads to the formation of a new carbon-carbon bond at the ortho or para positions with respect to the free hydroxyl groups in the two aryl rings. When there is a hydrogen at the site of coupling the ring can rearomatise by a simple enolisation. If there is a carbon substituent at the site of coupling straightforward aromatisation is not possible; the carbon skeleton may then remain unchanged in subsequent steps (morphine) or it may rearomatise either by migration of carbon-carbon bond (isothebaine) or by a fragmentation process (erythraline). The latter two processes greatly extend the range of skeletal types which may be formed as a consequence of oxidative coupling and this an important factor in accounting for the remarkable diversity of structure in the benzylisoquinoline alkaloid family.

I would like now to turn to recent work on the biosynthesis of protostephanine $[28,29]$. As we shall see this 


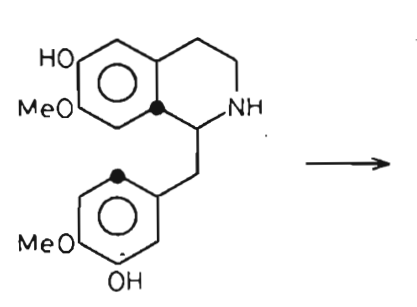

(56)

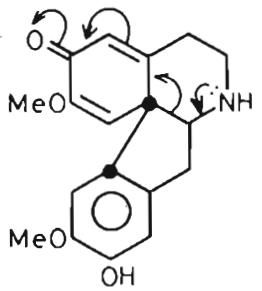

(57)

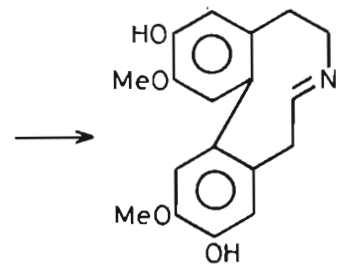

(58)

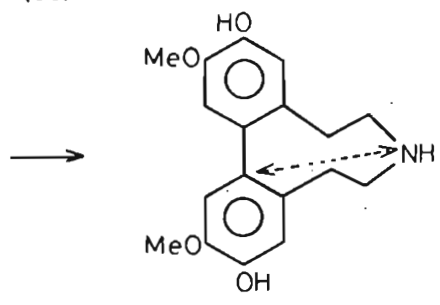

(59)

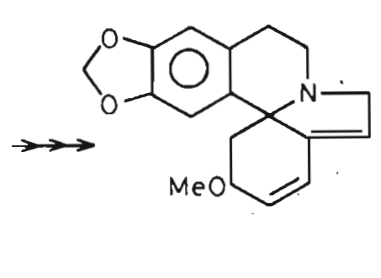

(60) Erythraline

Scheme 16 Biosynthesis of Erythrina Alkaloids

pathway is of interest not only because it makes use of both of the key processes but also because the oxidative coupling process seems to follow an unusual course. Moreover, the elucidation of the biosynthesis proved to be far from straightforward and so it makes an interesting case study to trace in some detail.

The structure of protostephanine is shown in Scheme 17 which also shows in outline the two most attractive hypotheses for its biosynthesis. Route (a) which was proposed by BARTON [30] involves oxidative coupling of a benzylisoquinoline intermediate (61) followed by skeletal modification. The alternative, (b), is more straighforward in that it involves oxidative coupling of a so-called open-chain amine (62) and thus leads directly to the skeleton of the alkaloid [31].

Of the two hypotheses, we favoured the former and so exploratory work cencentrated on possible benzylisoquinoline precursors. As indicated in structure (61) it seemed likely on mechanistic grounds that the precursor would be pentaoxygenated (one of the oxygens being lost subsequently in a dienol-benzene rearrangement). It was assumed in accord with all the precedents that there would be only one free hydroxyl group in each aryl ring the rest being protected as methoxy groups. These arguments lead to three candidates (64), (65) and (66). In the event all three gave negative results in precursor incorporation experiments. We were therefore forced to abandon this intuitive approach (which had proved gratifyingly successful in so many earlier investigations) in favour of patient detective work in which the pathway was traced forward step by step from the only known precursor, tyrosine.

The results of these endeavours are indicated in Scheme 18. At the outset 
<smiles>Oc1ccc(CC2CNCC2Cc2ccccc2)cc1</smiles>

(61)<smiles>CCN(C)C(Cc1ccc(O)cc1)Cc1ccc(OC)cc1</smiles>

(64)

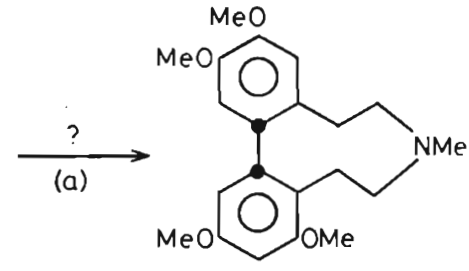

(63) Protostephanine

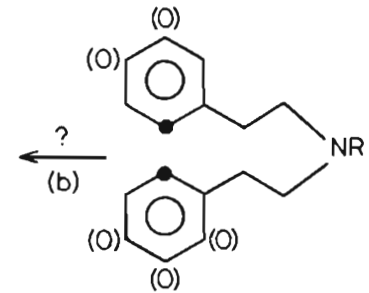

(62)

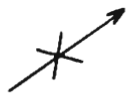

承

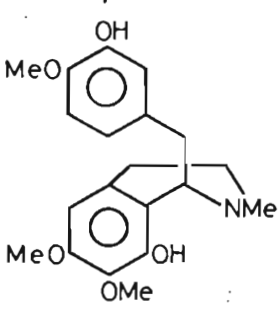

(65)

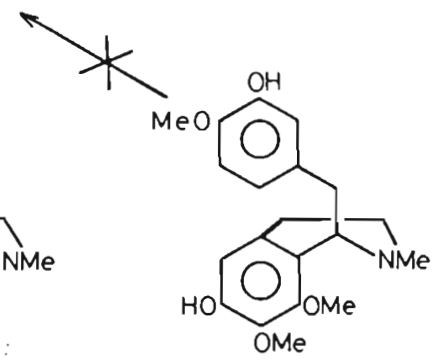

(66)

Scheme 17 Ideas and Experiments Relating to Protostephanine Biosynthesis

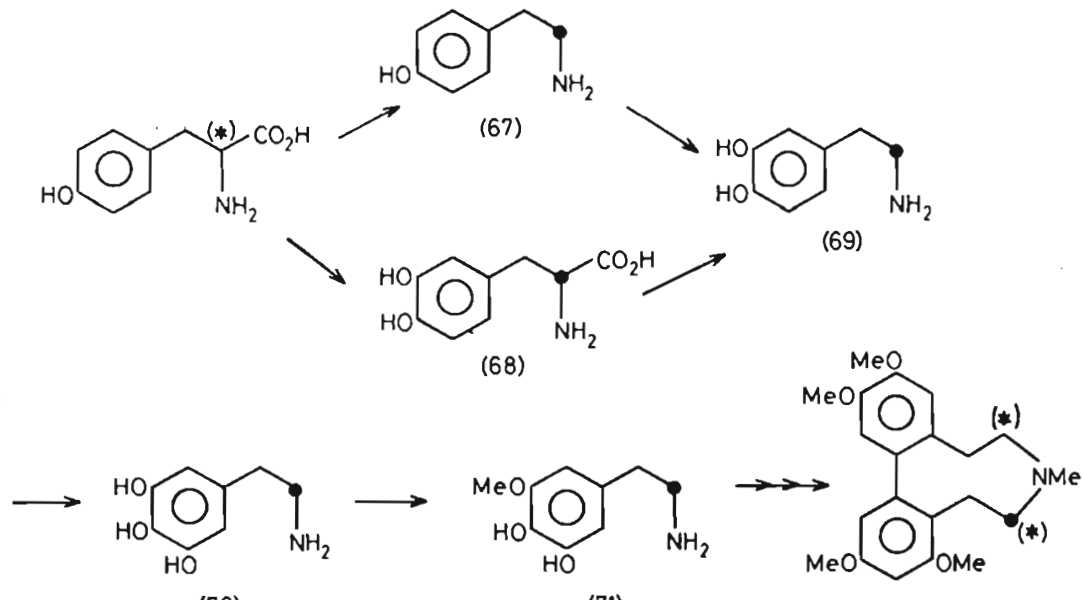

(70)

(71)

(63)

- and * $={ }^{14} \mathrm{C}$

Scheme 18 Incorporation of Phenethylamine Precursors into Protostephanine

tyrosine is converted to dopamine (69) via alternative intermediates tyramine (67) or dopa (68); from then on a linear pathway was traced via (70) as far as the phenethylamine (71). Each of these intermediates gave a significant incorporation which was moreover shown to be specific as indicated by degradation of the protostephanine. In contrast with these specific incorporations of 
phenethylamines, activity was incorporated from tyrosine into both "halves" of the molecule as indicated.

These results are consistent with the formation of benzylisoquinoline intermediates in later stages of the biosynthesis. Since both mono-methoxy derivatives of (71) gave negative incorporations it seemed likely that the first isoquinoline derivative to be formed would have in its phenethylamine unit the same pattern of hydroxyl and methoxy groups as this intermediate. Accordingly two classes of coupound represented by structures (72) and (73) were open to consideration. In each case the functionality of the aryl ring of the second building block could vary widely as indicated and a further source of variation lies the nature of the group attached to the nitrogen atom. In all sixteen benzylisoquinolines were candidates; every one was synthesised in specifically labelled form and tested as a precursor. We could not at that stage rule out the possibility that Boit's scheme might be correct in which case the next intermediates would be compounds of general structure (74). The four secondary amines corresponding to this structure were therefore tested as intermediates along with the benzylisoquinolines.
The resuls of this mammoth endeavour were very rewarding. Firstly all the open-chain compounds gave negative results. In contrast a number of benzyl isoquinolines gave positive incorporation results which allow us to define several more steps on the pathway leading to protostephanine. As shown in Scheme 20 the phenethylamine (71) is converted to the benzylisoquinoline (76) presumably by reaction with the ketoacid (75) (this has not been tested as a precursor yet). Both the secondary and tertiary amines depicted by (76) were incorporated and this was also true of intermediates (77) and (78). The timing of $\mathrm{N}$-methylation is therefore not clear and it is possible that two interconnected pathways operate in parallel at these stages of the biosynthesis. In contrast the order of the hydroxylation and methylation by which the functionality of the aryl ring is modified seems to be precisely defined because the remaining compounds of structure (72) were not incorporated to a significant extent.

The isoquinoline (78) is therefore the latest intermediate to be positively identified. In view of the negative results in our early incorporation experiments with its two mono-O-methyl derivatives, (64), and (65), we suggest

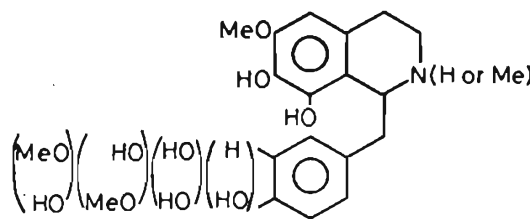

(72)

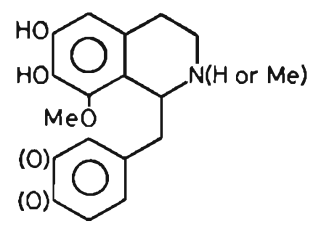

(73)

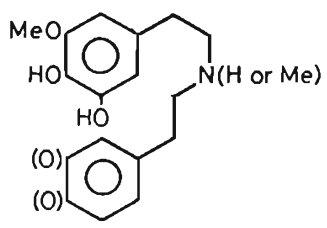

(74)

Scheme 19 Possible Late Precursors of Protostephanine 


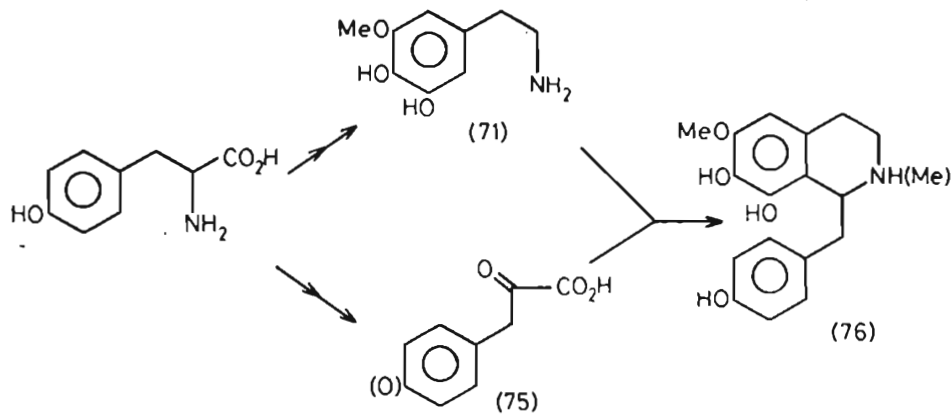

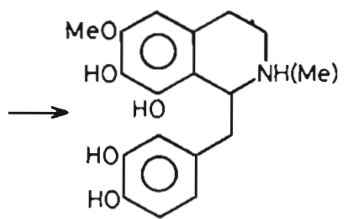

(77)

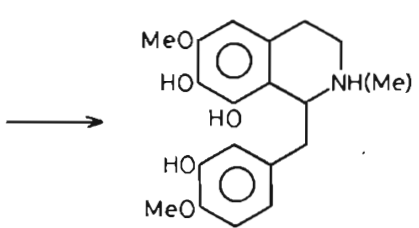

(78)

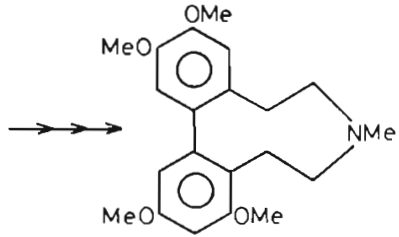

(63)

Scheme 20 Benzylisoquinoline Precursors of Protostephanine

that the next step of the biosynthesis may be intramolecular oxidative coupling of this intermediate (see Scheme 21). This suggestion will receive further comment below but for the moment we will concentrate on the subsequent hypothetical steps by which the intermediate dienone (80) might be converted to protostephanine. Note that a migration converts (81) to (82) followed by a fragmentation which is reminiscent of that which occurs in erythraline biosynthesis (Scheme 16). The subsequent steps which are not specified would be chemically trivial ones of reduction and methylation.

Hence this biosynthesis would combine both types of skeletal modification we have seen in earlier schemes. Its really intriguing feature is however the nature of the proposed oxidative coupling step. In every example considered so far there has been only one free hydroxyl group in each aryl ring of the substrate (that involved directly in the coupling process); the remaining oxygen functions have always been protected as methoxy groups. One of the striking features of the biosynthesis of morphine in Scheme 13 for instance is the way the two incidental oxygen functions of reticuline are protected as methoxyls prior to oxidative coupling, only to be demethylated in later stages of the biosynthesis. It is as though Nature in common with organic chemists needs to protect these extraneous oxygen functions prior to oxidative coupling so as to avoid undesirable side reactions. Indeed this appears to be so general a feature of oxidative coupling processes so far investigated in vivo, it has become almost a tenet of biosynthetic speculations. However as was mentioned earlier, the two monomethylated derivatives of (78) were not incorporated and we have therefore to consider seriously the possibility that the benzylisoquino- 


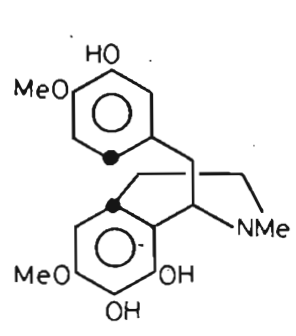

(78)

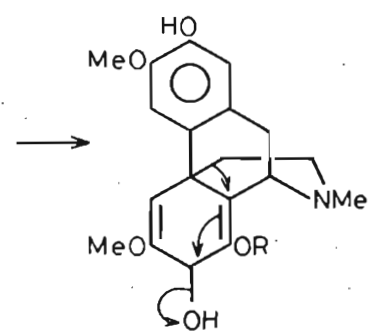

(81)
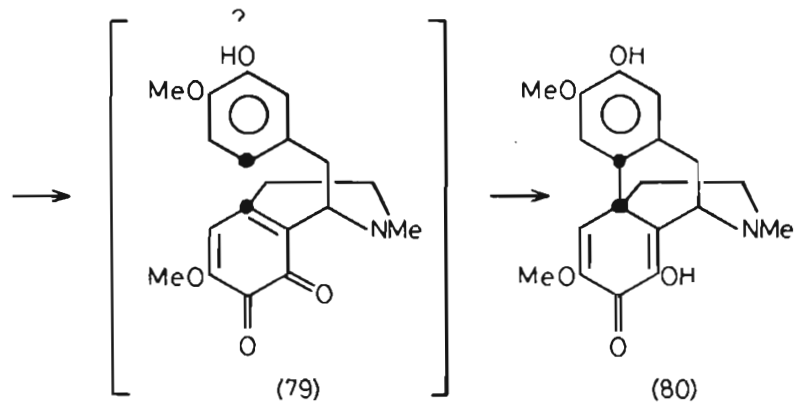

(80)

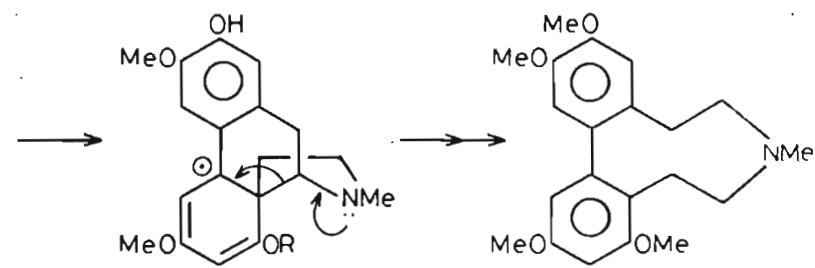

(82)

Scheme 21 Hypothesis for the Late Stages of Protostephanine Biosynthesis

line enters the phenol coupling step with two free hydroxyl groups in one of its aryl rings. That being so the oxidative coupling may involve nucleophilic addition to an orthoquinone in intermediate (79) rather than the usual coupling of a biradical. Obviously further experiments will be needed to substantiate this proposal. One cannot rule out the possibility that a protecting group other than methyl is employed in this case. Could the hydroxyl be protected as a glycoside derivative for example? Even so the biosynthesis would be exceptional and we are therefore keen to investigate the process further.

Finally it should be mentioned that the biosynthesis of hasubanonine (83) in Stephanica japonica shows the same unusual features $[28,28]$. The pathway is identical with that leading to proto- stephanine as far as the benzylisoquinoline (78). Again further methylation of the catechol system does not seem to take place prior to oxidative coupling. Clearly the subsequent steps (which are not specified in Scheme 22) must involve oxidative coupling between the marked carbons followed by migration of a $\mathrm{C}-\mathrm{N}$ bond. Once again the overall transformation of (78) to (83) shows several unusual features which warrant further investigation.

Before leaving this topic it is worth drawing attention to the profound modification of the methylation pattern in the lower aryl ring of (78) which occurs in going to (83): the two oxygens which were free in the precursor become methylated whereas the oxygen which starts out as a methoxy group becomes free. This biosynthesis therefore strikingly demonstrates the danger 


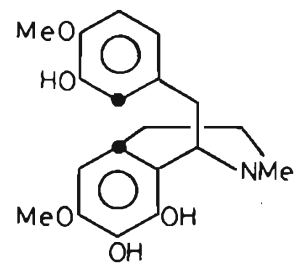

(78)

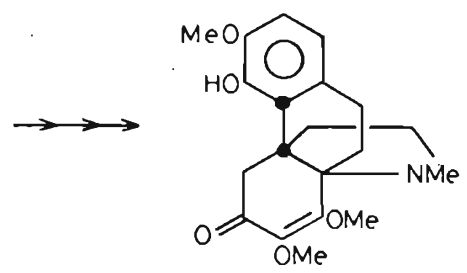

(83) Hasubanonine

Scheme 22 Biosynthesis of Hasubanonine

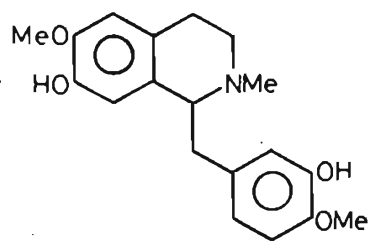

(36)

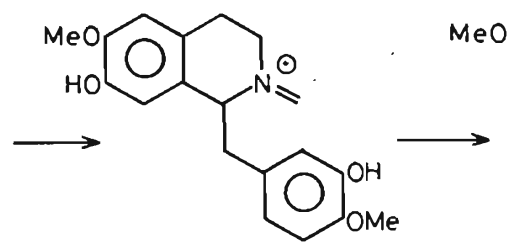

(84) of assuming that the pattern of derivatisation in an alkaloid provides a reliable clue to that which obtains in its precursors.

Though it provides a very flexible and widely used means of modifying the carbon skeleton of benylisoquinoline alkaloids, intramolecular oxidative coupling is not the only device used in Nature for this purpose. Before closing therefore we will briefly examine an alternative strategy which is widely used and which leads eventually to a variety of modified structures. The basic process shown in Scheme 23 leads to the formation of a protoberberine system. Again an oxidative cyclisation is used but this time it takes place between an aryl ring and a methyl group attached to nitrogen. Experimental support for the process is well documented $[32,33]$.

As was the case with the oxidative coupling of phenols the initial oxidation product is not necessarily the terminus of the biosynthetic pathway. Further modification of the protoberberine structure may take place leading to the production of many new systems. Some important examples are given in Scheme 24. The carbon skeletons of protopine (86) and narcotine (87) are produced by oxidative cleavage of C-N bonds (a) and (b) respectively [34, 35]. That of chelidonine (88) arises by cleavage of bond (c) followed by recyclisation at an alternative site [34].

The biosynthetic pathways leading to each of these alkaloids in Chelido- 


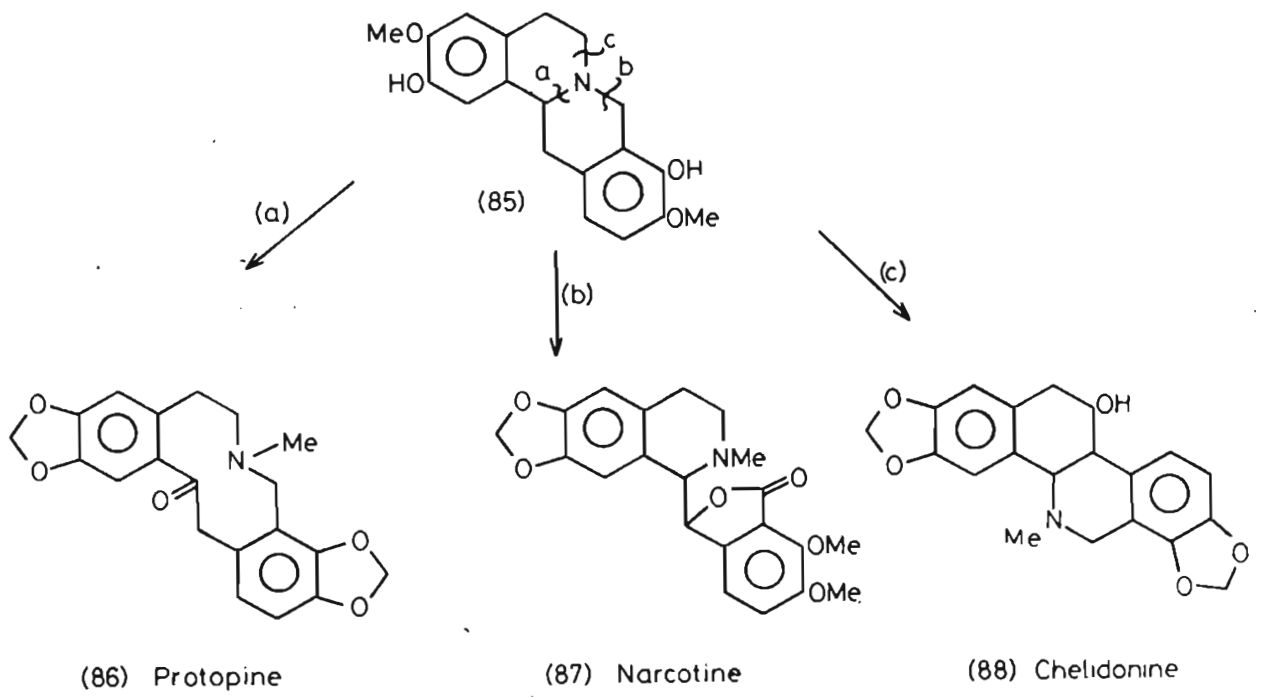

Scheme 24 Biosynthetic Transformations of Scoulerine

nium majus have been worked out in considerable detail but they will not be presented in detail here. Suffice it to say that these and other modifications of the protoberberine skeleton greatly extend the range of structural variants to be found in the isoquinoline family.

In conclusion, we can now claim to have a detailed knowledge of many of the more important biosynthetic pathways leading to isoquinoline alkaloids. Without exception these pathways are remarkable for the way in which a relatively small range of building blocks are transformed in one way or another to produce many diverse structures. The pathways involved are often long and complex and require many different enzymes.. Clearly alkaloids are not produced by accident: rather the plants go to great pains to make them. Why they should do so is for the most part still a complete mystery.

\section{References}

1. Leete, E.: J. Amer. Chem. Soc., 88, 4218 (1966).

2. Battersby, A. R., R. Binks and R. Huxtable: Tetrahedron Lett., 563 (1967).

3. Lundstrom, J. and S. Agurell: Tetrahedron Lett., 4437 (1968).

4. Battersby, A. R., R. Binks and R. Huxtable: Tetrahedron Lett., 6111 (1968).

5. Khanna, K. L., H. Rosenberg and A. G. Paul: J. C. S. Chem. Comm., 315 (1969).

6. Paul, A. G., K. L. Khanna, H. Rosenberg and M. Takido: J. C. S. Chem. Comm., 838 (1969).

7. Lundstrom J. and S. Agurell: Tetrahedron Lett., 3371 (1969).

Lundstrom, J.: Acta. Chem. Scand., 25, 3489 (1971).

8. Kapadia, G. J., G. Subba Rao, E. Leete, M. B. E. Fayez:

9. Vaishnav, Y. N. and H. M. Fales: J. Amer. Chem. Soc., 92, 6943, (1970).

10. O'Donovan, D. G. and H. Horan: J. Chem. Soc. (C), 2791 (1968).

11. Schütte, H. R. and G. Feelig: Liebig's Ann. Chem., 730, 186 (1969). 
12. O'Donovan, D. G. and E. Barry: J. C. S. Perkin I, 2528 (1974).

13. Battersby, A. R. and B. Gregory: J. C. S. Chem. Comm., 134 (1968).

14. Battersby, A. R., R. B. Herbert, E. McDonald, R. Ramage and (the late) J. H. Clements: J. C. S. Perkin I, 1741 (1972).

15. Battersby, A. R., R. C. F. Jones and R. Kazlauskas: Tetrahedron Lett., 1873 (1975).

16. Wilson, M. L. and C. J. Coscia: J. Amer. Chem. Soc., 97, 431 (1975).

17. Robinson, R.: Structural Relations of Natural Products, Clarendon Press, Oxford, (1955).

18. Barton, D. H. R. and T. Cohen: Festschr. A. Stolle, 117 (1957).

19. Brockmann-Hanssen, J., C.-C. Fu and L. Y. Misconi: J. Pharm. Sci., 60, 1880 (1971).

20. 'Tewari, S., D. S. Bhakuni and R. S. Kapil: J. C. S. Perkin I, 706 (19.77).

21. Barton, D. H. R., G. W. Kirby, W. Steglich, G. M. Thomas, A. R. Battersby, T. A. Dobson and H. Ramuz: J. Chem. Soc., 2423 (1965).

22. Blaschke, G., H. I. Parker and H. Rapoport: J. Amer. Chem. Soc., 89, 1540 (1967).

23. Battersby, A. R., J. A. Martin and E. Brockmann-Hanssen: J. Chem. Soc. (C), 1785 (1967).

24. Battersby, A. R., R. T. Brown, J. H. Clements and G. G. Iverach: J. C. S. Chem. Comm., 230 (1965).

25. Battersby, A. R., T. J. Brocksom and R. Ramage: J.C.S. Chem. Comm., 464 (1969).
26. Barton, D. H. R., R. B. Boar and D. A. Widdowson: J. Chem Soc. (C), 1213 (1970).

27. Barton, D. H. R., R. D. Bracho, C. J. Potter and D A. Widdowson: J. C. S. Perkin I, 2278 (1974).

28. Battersby, A. R., R. C. F. Jones, R. Kazlauskas, C. Poupat, C. W. Thornber, S. Ruchirawat and J. Staunton: J. C. S. Chem. Comm. 773 (1974).

29. Battersby; A. R., A. Minta, A. P. Ottridge and J. Staunton: Tetrahedron Letters, 1321 (1977).

30. Barton, D. H. R.: Pure and Applied Chem., 9, 35 (1964).

31. Boit, H. G.: Ergebnisse der Alkaloid-Chemie bis 1960, Akademie-Verlag, Berlin, 402 (1961).

32. Barton, D. H. R., R. H. Hesse and G. W. Kirby: J. Chem. Soc., 6379 (1965).

33. Battersby, A. R., R. J. Francis, M. Hirst, E. A. Ruveda and J. Staunton: J. C. S. Perkin I, 1140 (1975).

34. Battersby, A. R., J. Staunton, H. R. Wiltshire, R. J. Francis and R. Southgate: J. C. S. Perkin I, 1147 (1975).

35. Battersby, A. R., M. Hirst, D. J. McCaldin, R. Southgate and J. Staunton: J. Chem. Soc. (C), 2163 (1968).

Address:

Prof. Dr. J. Staunton University Chemical Laboratory Lensfield Road Cambridge - U. K. 